\title{
Chanceaux-sur-Choisille, ZAC de la Grande Pièce
} $n^{\circ} 068303$

Sébastien Jesset et Philippe Salé

\section{(2) OpenEdition}

\section{Journals}

Édition électronique

URL : http://journals.openedition.org/adlfi/13757

ISSN : 2114-0502

Éditeur

Ministère de la culture

Référence électronique

Sébastien Jesset et Philippe Salé, "Chanceaux-sur-Choisille, ZAC de la Grande Pièce », ADLFI.

Archéologie de la France - Informations [En ligne], Centre, mis en ligne le 28 octobre 2014, consulté le 19 avril 2019. URL : http://journals.openedition.org/adlfi/13757

Ce document a été généré automatiquement le 19 avril 2019

(C) Ministère de la Culture et de la Communication, CNRS 


\title{
Chanceaux-sur-Choisille, ZAC de la Grande Pièce
}

$\mathrm{n}^{\circ} 068303$

\author{
Sébastien Jesset et Philippe Salé
}

Lien Atlas (MCC) : http://atlas.patrimoines.culture.fr/atlas/trunk/index.php? ap_theme=DOM_2.01.02\&ap_bbox $=0.662 ; 47.452 ; 0.748 ; 47.500$

1 Le projet de création d'une zone d'aménagement concerté (ZAC) sur la commune de Chanceaux-sur-Choisille a nécessité la réalisation préalable d'un diagnostic archéologique. Ce projet, dénommé «ZAC de la Grande Pièce », s'intègre dans un espace situé au sud de l'agglomération, à environ $10 \mathrm{~km}$ au nord de Tours. Il consiste en la création d'un lotissement, dans la suite de la zone résidentielle qui se développe actuellement à l'est et au sud-est de Chanceaux. La réalisation de cette ZAC de 22 hectares est prévue en 2 tranches, et c'est sur la première, d'une superficie de d'environ 8 hectares, qu'ont porté les sondages archéologiques : 71 tranchées représentant environ $1400 \mathrm{~m}$ linéaires, ont ainsi été ouvertes.

2 Les connaissances archéologiques antérieures permettaient de supposer la présence, sur l'emprise, d'une voie gallo-romaine venant de Tours et se dirigeant vers le Mans. De plus, à quelques mètres au nord de la ZAC, et accolé à l'église Saint-Martin édifiée au cours des $\mathrm{X}^{\mathrm{e}}-\mathrm{XI}^{\mathrm{e}} \mathrm{s}$, un prieuré bénédictin du XII ${ }^{\mathrm{e}}$ siècle est encore en élévation. Une fuie, intégrée à un manoir du début du siècle, se trouve à une centaine de mètres au sud-ouest du prieuré ; sa position actuelle, éloignée des bâtiments, laisse supposer que les structures annexes du prieuré devaient s'étendre, à l'origine, au moins jusqu'à cette fuie. Enfin, au nord-est du prieuré, un ensemble formé d'une galerie desservant deux caves a été retrouvé en 1993 à la suite d'un effondrement du plafond de la cavité. La forme de la voûte, légèrement brisée, suggère une structure soit de l'époque carolingienne, soit des XIII- XIV $^{\mathrm{e}} \mathrm{s}$. 
Une première recherche, engagée aux archives départementales d'Indre-et-Loire dans les sources documentaires disponibles, a permis de retrouver un texte faisant mention de Chanceaux en 939. Il s'agit d'une confirmation de concession, faite par Robert, fidèle de Hugues le Grand, «dux francorum » et père de Hugues Capet, de la chapelle de la villa de Cancellis (Chanceaux) aux religieux de Saint-Julien de Tours.

4 Au terme de cette étude préliminaire, deux informations demandaient à être vérifiées :

- la première concerne la probable présence d'un tronçon de voie romaine, dans la partie ouest de l'emprise ;

- la seconde se rapporte à la proximité immédiate de la chapelle Saint-Martin, jouxtant un hypothétique habitat seigneurial et des bâtiments du prieuré transformés par la suite en ferme, qui ouvre la possibilité de trouver des éléments du haut Moyen Âge ou du Moyen Âge.

Une première occupation du Néolithique final ou de l'âge du Bronze doit être présente immédiatement au sud/sud-ouest de l'emprise. Elle a été mise en évidence uniquement par le mobilier lithique et céramique récolté dans les limons. La deuxième occupation, datée de La Tène finale et pressentie par la présence de mobilier céramique, doit probablement se situer au nord du site, à l'emplacement des occupations postérieures. L'occupation gallo-romaine qui lui succède est matérialisée par des structures en creux, vraisemblablement liées à un habitat; dans le même temps, les nombreuses scories retrouvées dans les comblements indiquent une activité métallurgique proche. En revanche, aucune trace de voirie n'a été mise en évidence sur l'emprise. Pour le haut Moyen Âge, l'occupation se caractérise par des fossés, des fosses et des trous de poteaux. A ces traces, il faut adjoindre les indices de la présence d'un four. Enfin, on a noté le rejet de plusieurs carcasses d'animaux. Les dernières traces d'occupation identifiées d'après le mobilier récolté ne dépassent pas le $\mathrm{VII}^{\mathrm{e}} \mathrm{s}$., voire le début du $\mathrm{VIII}^{\mathrm{e}} \mathrm{s}$.

6 Les sondages apportent la preuve qu'il s'agit d'un lieu habité de longue date. Les occupations se sont succédées sans grande rupture, se déplaçant au fur et à mesure vers le nord. La construction de la chapelle Saint-Martin pendant le haut Moyen Âge a donc dû se faire à proximité d'une occupation préexistante. La concession de Robert à l'abbaye de Saint-Julien ne peut être identifiée dans ce cas comme une terre neuve.

INDEX

Index géographique : Centre, Indre-et-Loire (37), Chanceaux-sur-Choisille

Mots-clés : céramique, métallurgie, four, prieuré

operation Sondage (SD)

Index chronologique : âge du Bronze, âge du Fer, Moyen Âge 